\title{
CARACTERÍSTICAS DA CARCACA DE OVINOS SANTA INÊS TERMINADOS EM PASTEJO E SUBMETIDOS A DIFERENTES NÍVEIS DE SUPLEMENTAÇÃO ${ }^{1}$
}

\author{
Carcass characteristics of Santa Inês sheep finished in grazing and submitted \\ to different levels of supplementation
}

\author{
Adriano Freitas Dantas 2 , José Morais Pereira Filho ${ }^{3}$, Aderbal Marcos de Azevedo Silva ${ }^{4}$, \\ Ecileide Mamede dos Santos ${ }^{5}$, Bonifácio Benício de Sousa ${ }^{4}$, Marcílio Fontes Cézar ${ }^{4}$
}

\begin{abstract}
RESUMO
Objetivou-se, com esse trabalho, avaliar as características da carcaça de cordeiros Santa Inês, mantidos em pastagem nativa e submetidos a diferentes níveis de suplementação na dieta $(1,5 \%, 1,0 \%$ e $0,0 \%$ do peso vivo). Foram utilizados 24 animais, machos castrados, com peso vivo (PV) médio inicial de $15 \mathrm{~kg} \pm 1,44$ e idade média de 150 dias. O concentrado foi constituído à base de milho moído, farelo de soja e sal mineral. O delineamento utilizado foi inteiramente casualizado, com três tratamentos e oito repetições. A utilização da suplementação possibilitou a obtenção de cordeiros com características mais desejáveis da carcaça, como: melhor rendimento, maior área de olho de lombo, menor perda de peso no resfriamento e maior peso dos cortes comerciais. Em termos de análise econômica, pode-se concluir que, se o objetivo for obter carcaças mais leves com peso em torno de 7 kg e com nível mínimo de gordura não há necessidade de suplementação com concentrado, mas, se o objetivo for obter carcaças pesando de $10 \mathrm{a} 12 \mathrm{~kg}$ e com melhor nível de acabamento recomenda-se suplementação com 1,0 a $1,5 \%$ do peso vivo com concentrado.
\end{abstract}

Termos para indexação: Cordeiros, corte comercial, perna, rendimento, semi-árido.

\section{ABSTRACT}

The aim of this study was to evaluate carcass characteristics of Santa Inês lambs, maintained in native pasture and submitted to different supplementation levels in the diet $(1,5 \%, 1,0 \%$ e $0,0 \%$ do LW). Twenty-four castrated sheep with $15 \pm 1,44 \mathrm{~kg}$ of mean live weight (LW) were used and average age of 150 days. The concentrate was constituted of cracked corn, soybean meal and mineral salt. A completely randomized design with three treatment and eight replicates was used. The use of the supplementation makes possible to get lambs with desirable characteristics of the carcass, such as: better yield, increase rib eye area, less lose of weight in the cooling, and greater weight of retail cuts. According to the economical analysis it may be concluded that, if the aim is to get lighter carcasses with weight around $7 \mathrm{~kg}$ and with minimum level of fat there is not any necessity of supplementation with concentrate, but, if the aim is to get the carcasses weighing from 10 to $12 \mathrm{~kg}$ and with better level of finishing, it is recommended supplementation with 1,0 to $1,5 \%$ of the live weight with concentrate.

Index terms: Lambs, leg, retail cuts, semi-arid, yield.

(Recebido em 5 de julho de 2007 e aprovado em 12 de fevereiro de 2008)

\section{INTRODUÇÃO}

A exploração agropecuária da região Nordeste do Brasil é amplamente afetada por fatores climáticos, dentre os quais, a precipitação pluviométrica e sua distribuição ao longo do ano, destacam-se por serem determinantes na disponibilidade e qualidade da pastagem, com conseqüências marcantes na produção animal, especialmente de caprinos e ovinos. No Nordeste, o efetivo ovino supera 8 milhões de cabeças, o que corresponde a aproximadamente 55\% do rebanho nacional. Mesmo assim, os sistemas de produção da região são dependentes da pastagem nativa (caatinga) e amargam baixos índices zootécnicos.

Segundo Cunha et al. (2000), a utilização de forragens de alta produtividade e elevado valor nutritivo é considerada uma alternativa viável para o desenvolvimento da ovinocultura do Nordeste, o que pode refletir, positivamente, no desempenho dos animais. Saniz (1996) destacou que as características da carcaça são influenciadas pela velocidade de crescimento, idade ao abate e regime nutricional dos animais. Por outro lado,

${ }^{1}$ Parte da dissertação de mestrado do primeiro autor apresentada à Universidade Federal de Campina Grande.

${ }^{2}$ Médico Veterinário, Mestre em Zootecnia - Rua José Vieira de Queiroga, s/n - Petrópolis - 58840-000 - Pombal, PB - adrianofd.vet@bol.com.br

${ }^{3}$ Médico Veterinário, Doutor em Zootecnia, Professor - Unidade Acadêmica de Medicina Veterinária/UAMV - Departamento de Medicina Veterinária/CSTR Universidade Federal de Campina Grande/UFCG - Avenida Universitária, s/n - Santa Cecília - Cx. P. 64 - 58700-970 - Patos, PB - jmpfpiaui@ig.com.br ${ }^{4}$ Zootecnistas, Doutores em Zootecnia, Professores - Unidade Acadêmica de Medicina Veterinária/UAMV - Departamento de Medicina Veterinária/CSTR Universidade Federal de Campina Grande/UFCG - Avenida Universitária, s/n - Santa Cecília - Cx. P. 64 - 58700-970 - Patos, PB - silvaama@gmail.com; bonifácio@cstr.edu.br; mfcezar@gmail.com

${ }^{5}$ Zootecnista, Mestre em Zootecnia - Rua Sérgio Lima, 22 - Jardim Guanabara - 58840-000 - Patos, PB - ecileidem@yahoo.com.br 
Neres et al. (2001) destacaram que, em pastagens nativas, dificilmente obtém-se boa produtividade e qualidade de carcaça ovina, devido principalmente à deficiência de nutrientes, havendo necessidade da utilização de pastagens cultivadas, suplementação em pastejo e/ou confinamento para explorar o máximo potencial genético dos animais.

Dentro deste contexto, a terminação de ovinos em regime de pasto com suplementação pode contribuir para a obtenção de animais mais jovens para o abate e oferecer ao consumidor carcaça de melhor qualidade. Portanto, objetivou-se, com esse trabalho, avaliar as características da carcaça de ovinos Santa Inês criados em pastagem nativa e submetidos a diferentes níveis de suplementação no semiárido paraibano.

\section{MATERIAL E MÉTODOS}

O experimento foi desenvolvido na Universidade Federal de Campina Grande, Campus de Patos-PB. O clima da região é classificado como quente e seco, sendo caracterizado por duas estações bem definidas, uma chuvosa, de janeiro a maio, e outra seca, de junho a dezembro, com médias anuais de $500 \mathrm{~mm}$ de precipitação, $29^{\circ} \mathrm{C}$ de temperatura, $60 \%$ de umidade relativa do ar e altitude de 300 metros. Os valores médios referentes à temperatura máxima e mínima durante o experimento foram de $34,6^{\circ} \mathrm{C}$ e $22,4^{\circ} \mathrm{C}$, a umidade relativa do ar apresentou média de $40,58 \%$ e não houve precipitação durante a pesquisa.

Foram utilizados 24 ovinos da raça Santa Inês, machos castrados, com peso vivo (PV) médio inicial de 15 $\mathrm{kg} \pm 1,44$ e idade média de 150 dias, os quais foram previamente identificados, vermifugados e, em grupos de três, foram distribuídos por sorteio em três níveis de suplementação, 0,0; 1,0 e 1,5\% do PV. Para monitorar o desempenho, os animais foram submetidos a jejum de 14 horas e pesados a cada quatorze dias.

A dieta foi constituída de pastagem nativa, enriquecida com capim buffel (Cenchrus ciliaris L. cv Biloela) e os níveis de suplementação. O concentrado foi constituído de 40,4\% de milho moído, 56,6\% de farelo de soja e $3 \%$ de sal mineral ${ }^{2}$, de forma que a dieta com maior suplementação atendesse às recomendações do AFRC (1993), para um ganho de $200 \mathrm{~g} / \mathrm{cab} / \mathrm{dia}$. Os animais foram mantidos em pastejo das 7:00 às 16:00 horas, quando eram recolhidos às baias para serem suplementados. A composição química dos componentes da pastagem nativa e do concentrado é descrita Tabela 1 .

Para estimativa da disponibilidade de matéria seca (Tabela 2), foi procedido um levantamento da disponibilidade de forragem no início (agosto) e no final (outubro) do ensaio experimental. Para tanto, vinte e quatro amostras foram coletadas seguindo a metodologia de Araújo Filho et al. (1998). Cada amostra foi separada em gramíneas e dicotiledôneas herbáceas, pesadas in natura, submetidas à pré-secagem, moídas e posteriormente utilizadas para análise química.

$\mathrm{O}$ abate foi realizado na medida em que dos animais do tratamento $1,5 \%$ atingiam $30 \mathrm{~kg}$ de PV, juntamente com seus pares dos demais tratamentos. Antes do abate, os animais foram submetidos a jejum de 16 horas de dieta sólida e líquida.

O abate foi realizado através de atordoamento e sangria da veia jugular e artéria carótida, com coleta e pesagem do sangue. Em seguida foi feita a esfola e a evisceração. O trato gastrintestinal (TGI), a bexiga e a vesícula biliar foram esvaziados e limpos para a obtenção do peso do corpo vazio (PCV), que foi obtido subtraindo-se do peso ao abate (PA), os pesos referentes ao conteúdo do TGI e aos líquidos contidos na bexiga e na vesícula biliar.

Tabela 1 - Composição química do concentrado e da forragem disponível.

\begin{tabular}{|c|c|c|c|}
\hline Constituinte & Concentrado & Gramíneas & Dicotiledôneas herbáceas \\
\hline Matéria seca (\%) & 90,83 & 66,54 & 50,63 \\
\hline Matéria mineral $(\%)^{1}$ & 6,64 & 7,30 & 6,70 \\
\hline Proteína bruta $(\%)^{\mathbf{1}}$ & 27,84 & 4,08 & 9,22 \\
\hline Energia bruta (Kcal/kg) & 5490 & 4479 & 4418 \\
\hline Fibra em detergente neutro $(\%)^{1}$ & 8,45 & 79,27 & 68,31 \\
\hline Fibra em detergente ácido $(\%)^{1}$ & 3,91 & 68,31 & 45,75 \\
\hline
\end{tabular}

$1=\%$ da matéria seca

2Participação porcentual na mistura. Calcário calcítrico 12,1; fosfato bicálcico 39; enxofre 0; iodeto de potássio 0,01; sulfato de manganês 1,000; sulfato de zinco 0,500 ; selenito de sódio 0,005 ; sulfato de cobre 0,211 ; sulfato de cobalto 0,047 ; sal comum 47,127 ; total 100,00 . 
Tabela 2-Disponibilidade de matéria seca (Disp.MS), composição florística e digestibilidade da matéria seca (DMS) da vegetação herbácea, na área de pastejo.

\begin{tabular}{lccc}
\hline \multicolumn{1}{c}{ Componente florístico } & Disp.MS (kg/ha) & Composição florística (\%) & DMS (\%)* \\
\hline Gramíneas & $2.252,8$ & 56,32 & 45,28 \\
Dicotiledôneas herbáceas & $1.746,4$ & 43,66 & 62,06 \\
\hline
\end{tabular}

* Obtida através do FDNi (fibra em detergente neutro insolúvel)

Após a separação dos componentes nãoconstituintes da carcaça foi obtido o peso da carcaça quente (PCQ), que foi utilizado para estimar o rendimento de carcaça quente $(\mathrm{RCQ}=\mathrm{PCQ} / \mathrm{PA} \times 100)$. $\mathrm{O}$ rendimento biológico $(\mathrm{RB})$ foi obtido a partir da razão entre o peso da carcaça quente e o peso de corpo vazio $(\mathrm{RB}=\mathrm{PCQ} / \mathrm{PCV} \mathrm{x}$ 100). Em seguida, as carcaças foram resfriadas em câmara fria a $5^{\circ} \mathrm{C}$ durante 24 horas, e ao final desse período as carcaças foram pesadas para a obtenção do peso da carcaça fria (PCF), que foi utilizado para estimar o rendimento da carcaça fria $(\mathrm{RCF}=\mathrm{PCF} / \mathrm{PA} \times 100)$. $\mathrm{O}$ porcentual de perda de peso da carcaça pelo resfriamento foi obtido pela fórmula PPR $=((\mathrm{PCQ}-\mathrm{PCF}) / \mathrm{PCQ}) \times 100$.

As carcaças foram divididas longitudinalmente $\mathrm{e}$ na meia carcaça esquerda foram realizadas as seguintes mensurações: comprimento interno da carcaça, comprimento da perna, perímetro da perna, largura da perna e profundidade do peito. Em seguida, a meia carcaça foi dividida em cinco cortes comerciais: perna, lombo, costelas, paleta e pescoço, os quais foram pesados para cálculo dos seus rendimentos em relação ao peso da carcaça. Entre a $12^{\mathrm{a}}$ e a $13^{\mathrm{a}}$ vértebras torácicas, foi realizado um corte para expor a secção transversal do músculo Longíssimus dorsi, sobre o qual foi traçada a área de olho do lombo (AOL) em película transparente e em seguida foram efetuadas mensurações para a obtenção da referida área, conforme metodologia de Silva Sobrinho (1999).

Para o cálculo do custo da suplementação, os ingredientes foram cotados em outubro de 2004, considerando o preço médio adotado na região de PatosPB e quando o câmbio era de U\$1,00:R \$2,90. Assim, o custo do suplemento mineral foi de $\mathrm{R} \$ 0,66 / \mathrm{kg}$, o custo final do concentrado foi de $\mathrm{R} \$ 0,56 / \mathrm{kg}$.

É importante mencionar que a análise econômica consistiu do custo com a obtenção do borrego e do custo com alimentação. Os custos com instalações e mão-deobra variam em função das características de cada sistema de produção e seriam "fixos" para sistemas semelhantes que adotassem as mesmas condições de manejo. A análise econômica considerou que todos os animais com $15 \mathrm{~kg}$ foram comprados por $\mathrm{R} \$ 2,50 / \mathrm{kg}$ de $\mathrm{PV}$, portanto a análise econômica reflete tão somente os custos com alimentação.
As variáveis utilizadas para a análise econômica foram as recomendadas por Lana et al. (1999), descritas da seguinte forma: Receita bruta média (RBM): obtida multiplicando o peso do ovino (PO) pelo preço do $\mathrm{kg}$ de PV (PçkgPV), definida por: RBM = PO x PçkgPV; Custos com alimentação $(\mathrm{CuA})$ : obtido multiplicando o total de ração consumida (RC) pelo seu respectivo preço (PçR), definido por: $\mathrm{CuA}=\mathrm{RC}$ x PçR; Margem bruta média (MBM): obtida pela diferença entre a receita bruta e os custos com alimentação, definida como: $\mathrm{MBM}=\mathrm{RBM}-\mathrm{CuA}$.

$\mathrm{O}$ delineamento experimental utilizado foi inteiramente casualizado, com três tratamentos e oito repetições. Na análise estatística foi utilizado o programa estatístico SAS Institute (1999), com os dados sendo submetidos a análises de variância e as médias comparadas pelo teste de Tukey, ao nível de 5\% de probabilidade.

\section{RESULTADOS E DISCUSSÃO}

Embora o desempenho dos animais não tenha sido objeto de estudo deste trabalho, destaca-se que os níveis de suplementação proporcionaram diferenças no ganho de peso dos animais. Os animais suplementados com 1,5\% e 1,0\% do peso vivo em concentrado, apresentaram ganho médio diário de 192 e 148g, respectivamente, o que pode ser explicado pelos níveis de proteína e energia da dieta, repercutindo em maior deposição de tecido muscular e adiposo, principalmente nos ovinos que receberam maior nível de suplementação. Para os animais não suplementados, o ganho médio diário foi de $90 \mathrm{~g}$, refletindo a disponibilidade e a digestibilidade da forragem, que foi de $45,28 \%$ para gramíneas e $62,06 \%$ para dicotiledôneas herbáceas.

Os resultados relativos às medidas da carcaça são descritos na Tabela 3. Observa-se que o comprimento interno da carcaça, comprimento da perna, profundidade do peito e perímetro da perna não foram influenciados $(\mathrm{p}>0,05)$ pela suplementação. A largura da perna foi semelhante nos tratamentos $0,0 \%$ e $1,0 \%$, mas ambos foram inferiores ao obtido no tratamento, com $1,5 \%$ de suplementação.

Quanto à compacidade da carcaça, observa-se influência da suplementação em todos os tratamentos, o 
Tabela 3 - Médias, coeficientes de variação das medidas da carcaça de ovinos Santa Inês, terminados em pastagem nativa com diferentes níveis de suplementação.

\begin{tabular}{lcccc}
\hline \multirow{2}{*}{ Variável } & \multicolumn{3}{c}{ Nível de Suplementação (\% do PV) } & \multirow{2}{*}{ CV\% } \\
\cline { 2 - 4 } & 0,0 & 1,0 & 1,5 & \\
\hline Comprimento interno da carcaça $(\mathrm{cm})$ & $51,18 \mathrm{a}$ & $51,75 \mathrm{a}$ & $56,00 \mathrm{a}$ & 8,15 \\
Comprimento da perna $(\mathrm{cm})$ & $33,00 \mathrm{a}$ & $32,92 \mathrm{a}$ & $35,43 \mathrm{a}$ & 6,19 \\
Profundidade do peito $(\mathrm{cm})$ & $22,72 \mathrm{a}$ & $22,67 \mathrm{a}$ & $24,00 \mathrm{a}$ & 5,76 \\
Largura da perna $(\mathrm{cm})$ & $6,56 \mathrm{~b}$ & $6,78 \mathrm{~b}$ & $8,06 \mathrm{a}$ & 10,06 \\
Perímetro da perna $(\mathrm{cm})$ & $11,57 \mathrm{a}$ & $11,18 \mathrm{a}$ & $11,62 \mathrm{a}$ & 14,75 \\
Compacidade da carcaça $(\mathrm{kg} / \mathrm{cm})$ & $0,129 \mathrm{c}$ & $0,162 \mathrm{~b}$ & $0,194 \mathrm{a}$ & 8,68 \\
\hline
\end{tabular}

Médias com letras diferentes na mesma linha diferem $(\mathrm{p}<0,05)$, pelo teste de Tukey.

que pode ser explicado pelas variações no peso das carcaças, visto que o comprimento não variou em função da suplementação. Siqueira et al. (2001) destaca compacidade superior para animais sacrificados com maior peso, fato também verificado neste trabalho, com os animais que receberam maior nível de suplementação, que apresentaram maiores peso, indicando maior deposição de tecido muscular e adiposo, provavelmente em conseqüência do maior aporte de nutrientes, na dieta dos animais suplementados.

O peso do conteúdo gastrintestinal, bem como o peso e rendimento da carcaça estão apresentados na Tabela 4. Observa-se que, somente o peso do conteúdo gastrintestinal e o rendimento biológico não foram influenciados $(p>0,05)$ pelos níveis de suplementação, podendo ser associados ao período de jejum de 16 horas a que os animais foram submetidos, dando tempo aos animais dos diferentes tratamentos alcançarem o mesmo nível de retenção de conteúdos sólidos e líquidos.

Os animais suplementados com $1,5 \%$ de concentrado apresentaram PCQ, PCF, PCV, RCQ e RCF maiores ( $\mathrm{p}<0,05)$ que os observados nos animais do tratamento $1,0 \%$, seguidos dos obtidos em $0,0 \%$. A diferença entre o peso de abate, pode ser relacionada à metodologia que preconizou o abate para o momento em que os animais do maior nível de suplementação atingissem $30 \mathrm{~kg}$, os quais seriam abatidos junto com seus pares dos demais tratamentos, o que repercutiu na diferença observada nos pesos da carcaça e de corpo vazio. Embora o PCV tenha variado entre os tratamentos proporcionalmente ao nível de suplementação, não houve efeito significativo para rendimento biológico, muito provavelmente devido à semelhança no peso do conteúdo gastrintestinal.

Uma vez interferindo no peso de abate dos animais, o uso da suplementação alimentar alterou o PCQ e o PCF o que, por sua vez, refletiu-se nos respectivos rendimentos, com o RCQ e o RCF crescendo progressivamente com o aumento da suplementação, obtendo-se, no tratamento $1,5 \%, 43,60 \%$ e $40,25 \%$, respectivamente.

Segundo Siqueira (2000), os altos rendimentos podem estar associados à baixa porcentagem de componentes não-constituintes da carcaça, porém, eles não são suficientes para justificar a progressiva alteração dos rendimentos em relação aos níveis de suplementação alimentar, o que pode estar relacionado à maior deposição de tecido adiposo nos animais suplementados, bem como à semelhança no peso do conteúdo gastrintestinal, que foi igual em todos os tratamentos.

A perda de peso pelo resfriamento foi menor no tratamento $1,5 \%$ em relação ao tratamento $0,0 \%$. Esse resultado pode ser explicado por uma maior deposição de gordura nos animais suplementados com 1,5\% do PV. A gordura proporciona menores perdas de água da carcaça desses animais, quando colocados em resfriamento (SILVA SOBRINHO, 1999), pois confere proteção à carcaça. Com relação a AOL, observou-se que os animais do tratamento $1,5 \%$ apresentaram AOL maiores $(\mathrm{p}<0,05)$ que as observadas nos animais de $1,0 \%$, seguidos dos obtidos nos animais de $0,0 \%$, confirmando o mesmo comportamento observado para peso e rendimento da carcaça, ou seja, maiores níveis de suplementação conferindo PCF e RCF mais elevados e conseqüentemente maiores AOL.

$\mathrm{Na}$ Tabela 5, são apresentados os resultados referentes ao peso e rendimento dos cortes comerciais de acordo com os níveis de suplementação. Observa-se que o maior nível de suplementação influenciou $(\mathrm{p}<0,05)$ os pesos de perna, lombo, costilhar, paleta e pescoço, corroborando a constatação de que o somatório dos cortes, ou seja, o PCF variou na mesma proporção. 
Tabela 4 - Médias e coeficientes de variação (CV) para peso ao abate, peso do conteúdo gastrintestinal, peso e rendimento da carcaça quente e da carcaça fria, peso de corpo vazio, rendimento biológico, perda pelo resfriamento, e área de olho de lombo (AOL) de ovinos Santa Inês, terminados em pastagem nativa com diferentes níveis de suplementação.

\begin{tabular}{lccrc}
\hline \multirow{2}{*}{ Variável } & \multicolumn{3}{c}{ Nível de Suplementação (\% do PV) } & \multirow{2}{*}{ CV (\%) } \\
\cline { 2 - 4 } & \multicolumn{1}{c}{0,0} & 1,0 & 1,5 & \\
\hline Peso ao abate $(\mathrm{kg})$ & $20,54 \mathrm{c}$ & $23,63 \mathrm{~b}$ & $27,09 \mathrm{a}$ & 9,75 \\
Peso do conteúdo gastrintestinal $(\mathrm{kg})$ & $5,84 \mathrm{a}$ & $6,07 \mathrm{a}$ & $5,86 \mathrm{a}$ & 14,36 \\
Peso da carcaça quente $(\mathrm{kg})$ & $7,66 \mathrm{c}$ & $9,55 \mathrm{~b}$ & $11,80 \mathrm{a}$ & 12,89 \\
Peso da carcaça fria $(\mathrm{kg})$ & $6,95 \mathrm{c}$ & $8,70 \mathrm{~b}$ & $10,90 \mathrm{a}$ & 12,44 \\
Peso do corpo vazio $(\mathrm{kg})$ & $14,70 \mathrm{c}$ & $17,55 \mathrm{~b}$ & $21,22 \mathrm{a}$ & 10,25 \\
Perda pelo resfriamento $(\mathrm{kg})$ & $4,18 \mathrm{a}$ & $3,33 \mathrm{ab}$ & $2,88 \mathrm{~b}$ & 24,84 \\
Rendimento de carcaça quente $(\%)$ & $37,11 \mathrm{c}$ & $40,39 \mathrm{~b}$ & $43,60 \mathrm{a}$ & 6,25 \\
Rendimento de carcaça fria $(\%)$ & $33,68 \mathrm{c}$ & $36,68 \mathrm{~b}$ & $40,25 \mathrm{a}$ & 6,24 \\
Rendimento biológico $(\%)$ & $51,92 \mathrm{a}$ & $54,37 \mathrm{a}$ & $55,62 \mathrm{a}$ & 5,48 \\
Área de olho de lombo $\left(\mathrm{cm}^{2}\right)$ & $7,51 \mathrm{c}$ & $9,16 \mathrm{~b}$ & $10,81 \mathrm{a}$ & 14,23 \\
\hline
\end{tabular}

Médias com letras diferentes na mesma linha diferem $(\mathrm{p}<0,05)$, pelo teste de Tukey.

Tabela 5 - Médias e coeficientes de variação (CV) para os pesos (g) e rendimento (\%) dos cortes comerciais de ovinos Santa Inês, terminados em pastagem nativa com diferentes níveis de suplementação.

\begin{tabular}{lcccc}
\hline \multirow{2}{*}{\multicolumn{1}{c}{ Variável }} & \multicolumn{2}{c}{ Nível de Suplementação (\% do PV) } & \multirow{2}{*}{ CV\% } \\
\cline { 2 - 4 } & 0,0 & 1,0 & 1,5 & \\
\hline Peso da Perna (g) & $1172,50 \mathrm{c}$ & $1475,00 \mathrm{~b}$ & $1816,50 \mathrm{a}$ & 10,82 \\
Peso do Lombo (g) & $350,00 \mathrm{~b}$ & $436,00 \mathrm{~b}$ & $553,25 \mathrm{a}$ & 16,41 \\
Peso do Costilhar (g) & $891,00 \mathrm{c}$ & $1213,75 \mathrm{~b}$ & $1422,50 \mathrm{a}$ & 12,23 \\
Peso da Paleta (g) & $743,50 \mathrm{~b}$ & $851,25 \mathrm{~b}$ & $1077,00 \mathrm{a}$ & 11,31 \\
Peso do Pescoço (g) & $262,50 \mathrm{~b}$ & $327,75 \mathrm{~b}$ & $435,25 \mathrm{a}$ & 21,54 \\
Rendimento de perna (\%) & $34,29 \mathrm{a}$ & $34,32 \mathrm{a}$ & $34,25 \mathrm{a}$ & 3,68 \\
Rendimento de lombo (\%) & $10,26 \mathrm{a}$ & $10,06 \mathrm{a}$ & $10,43 \mathrm{a}$ & 10,71 \\
Rendimento de costilhar (\%) & $26,04 \mathrm{~b}$ & $28,18 \mathrm{a}$ & $26,83 \mathrm{ab}$ & 5,45 \\
Rendimento de paleta (\%) & $21,72 \mathrm{a}$ & $19,87 \mathrm{~b}$ & $20,30 \mathrm{~b}$ & 4,98 \\
Rendimento de pescoço (\%) & $7,68 \mathrm{a}$ & $7,55 \mathrm{a}$ & $8,18 \mathrm{a}$ & 15,34 \\
\hline
\end{tabular}

Médias com letras diferentes na mesma linha diferem $(\mathrm{p}<0,05)$, pelo teste de Tukey.

Resultados semelhantes foram reportados por Gonzaga Neto et al. (2006), que ao avaliarem os efeitos de diferentes níveis de concentrado, (30, 45 e 60\%), na dieta de cordeiros Morada Nova em confinamento, observaram crescimento linear para peso de todos os cortes, em função do aumento do concentrado na dieta. As diferenças obtidas para os cortes entre os tratamentos refletem principalmente o maior crescimento de músculos nos animais suplementados, visto que a gordura apresenta crescimento tecidual lento, e o tecido ósseo crescimento precoce, justificando, segundo Rosa et al. (2002), o progressivo desenvolvimento em função dos diferentes níveis de suplementação, e a maior atividade física dos animais não suplementados (ANIMUT et al., 2005), o que resulta em maiores exigências nutricionais (SANTOS, 2006). 
Os resultados obtidos para peso dos diferentes cortes, especialmente para perna, lombo e costilhar indicam que a suplementação proporciona maior peso de carcaça, o que pode estar relacionado ao aumento da participação de tecido muscular no tratamento $1,0 \%$, e muscular e adiposo no tratamento $1,5 \%$ do PV, confirmando a ordem de prioridade de deposição dos tecidos, sendo primeiro osso, seguido de músculos e finalmente gordura (BOGGS, 1998).

Com relação às participações porcentuais dos cortes comerciais, observou-se que o rendimento de perna, lombo e pescoço não foram influenciados pela suplementação, demonstrando comportamento diferente do observado para os pesos absolutos desses cortes. Esses resultados confirmam a lei da harmonia anatômica (BOCARD, citado por SIQUEIRA, 2000), a partir da verificação de que carcaças (todo) com pesos diferentes refletem em cortes (parte) de pesos variados, mas em termos proporcionais à variação na carcaça nem sempre implica em variação do corte, o que pode ser associado a possíveis diferenças no crescimento dos tecidos, principalmente músculo e gordura.

Os resultados desse experimento, para rendimento dos cortes de carcaça de cordeiros Santa Inês em regime de pasto estão próximos aos encontrados por Ortiz et al. (2005), que ao avaliarem o efeito de três níveis de proteína 15,20 e 25\% PB na ração, de cordeiros Suffolk alimentados e terminados em creep feeding, obtiveram rendimentos de $34,93,10,68,19,92$ e $9,24 \%$ para perna, lombo, paleta e pescoço, respectivamente. Rufino (2005), trabalhando com desempenho de cordeiros Santa Inês em pastejo com suplementação de $300 \mathrm{~g} /$ dia e abatido aos $30 \mathrm{~kg}$ de PV, encontrou rendimento de $34,47,10,11,25,45,20,04$ e $9,91 \%$ para perna, lombo, costilhar, paleta, e pescoço, respectivamente.

Na Tabela 6, são apresentados os resultados referentes à análise econômica dos diferentes níveis de suplementação. Observa-se que o consumo, o custo com alimentação e a renda bruta média variaram estatisticamente com os níveis de suplementação, fato esse que já era esperado, tendo em vista que os animais apresentavam PV inicial semelhante e a metodologia estabeleceu que, no momento em que os animais suplementados com $1,5 \%$ do peso vivo atingissem $30 \mathrm{~kg}$, seriam abatidos juntamente com os seus pares dos demais tratamentos, ou seja, com menores pesos.

Como era de se esperar a renda bruta média aumentou com a suplementação, refletindo claramente os diferentes pesos de abate preconizados pela metodologia, mas a margem bruta média foi de 13,68, 12,98 e 14,39 reais por animal para os tratamentos com $0 ; 1,0 \mathrm{e}$ $1,5 \%$ de suplementação, não havendo efeito $(\mathrm{p}>0,05)$ dos níveis de suplementação nessa variável. Ao se considerar apenas os resultados da análise econômica, a suplementação seria facultativa, mas se for levado em conta os diferentes pesos de bate a suplementação pode ser justificada devido às exigências do mercado, que normalmente demanda carcaças de aproximadamente 12 a $13 \mathrm{~kg}$, as quais, normalmente, são oriundas de animais pesando em torno de $30 \mathrm{~kg}$ de PV.

\section{CONCLUSÃO}

O incremento da suplementação na dieta de cordeiro Santa Inês em regime de pasto, nas condições de clima semi-árido, possibilita a obtenção de carcaças mais pesadas, com melhores rendimentos e menor perda de peso durante o resfriamento.

Embora a suplementação não tenha sido positiva para rendimento dos cortes comerciais, a análise econômica indica que, se o objetivo for obter carcaças que melhor atendam o mercado consumidor, ou seja, pesando de 9 a $12 \mathrm{~kg}$ e com melhor nível de acabamento, recomenda-se a suplementação com concentrado, na proporção de 1,0 a $1,5 \%$ do peso vivo.

Tabela 6 - Médias das variáveis utilizadas na análise econômica de ovinos Santa Inês, terminados em pastagem nativa e submetidos a diferentes níveis de suplementação.

\begin{tabular}{lccc}
\hline \multirow{2}{*}{ Variável } & \multicolumn{3}{c}{ Nível de Suplementação (\% do PV) } \\
\cline { 2 - 4 } & $0,0^{*}$ & 1,0 & 1,5 \\
\hline Consumo (kg) & $1,77 \mathrm{c}$ & $19,81 \mathrm{~b}$ & $32,52 \mathrm{a}$ \\
Custos com alimentação (R\$) & $1,10 \mathrm{c}$ & $11,10 \mathrm{~b}$ & $18,21 \mathrm{a}$ \\
Renda bruta média (R\$) & $14,95 \mathrm{c}$ & $24,08 \mathrm{~b}$ & $32,61 \mathrm{a}$ \\
Margem bruta média (R\$) & $13,86 \mathrm{a}$ & $12,98^{\mathrm{a}}$ & $14,39 \mathrm{a}$ \\
\hline
\end{tabular}

Médias com letras diferentes na mesma linha diferem $(\mathrm{p}<0,05)$, pelo teste de Tukey.

* Correspondente aos custos com mineralização. 


\section{REFERÊNCIAS BIBLIOGRÁFICAS}

AGRICUTURALAND FOOD RESEARCH COUNCIL. The nutrition of sheep. Walhingford: CAB Internacional, 1993. $118 \mathrm{p}$.

ANIMUT, G.; GOETSCH, A. L.; AIKEN, G. E.; PUCHALA, R.; DETWEILER G.; KREHBIEL, C. R.; MERKEL, R. C.; SAHLU, T.; DAWSOND, L. J.; JOHNSON, Z. B.; GIPSON, T. A. Grazing behavior and energy expenditure by sheep and goats co-grazing grass/forb pastures at three stocking rates. Small Ruminants Research, Amsterdam, v. 59, p. 191-201, 2005.

ARAÚJO FILHO, J. A.; LEITE, E. R.; SILVA, N. L. Contribution of wood species to the diet composition of goat and sheep in caatinga vegetation. Pasturas Tropicales, Cali, v. 20, p. 41-45, 1998.

BOGGS, D. L.; MERKEL, R. A.; DOUMIT, M. E. Livestock and carcasses: an integrated approach to evaluation, grading and selection. Kenda: Hunt, 1998. 329 p.

CUNHA, E. A.; BUENO, M. S.; SANTOS, L. E. Produção ovina em pastagens. In: CONGRESSO NORDESTINO DE PRODUÇÃO ANIMAL, 2.; SIMPÓSIO NORDESTINO DE ALIMENTAÇÃO DE RUMINANTES, 8., 2000, Teresina, PI. Anais... Teresina: Sociedade Nordestina de Produção Animal, 2000. p. 181-190.

GONZAGA NETO, S.; SILVA SOBRINHO, A. G.; ZEOLA, N. M. L.; MARQUES, C. A. T.; SILVA, A. M. A.; PEREIRA FILHO, J. M.; FEREIRA, A. C. D. Características quantitativas da carcaça de cordeiros deslanados Morada Nova em função da relação volumoso:concentrado na dieta. Revista Brasileira de Zootecnia, Viçosa, v. 35, n. 4, p. 1487 1495, 2006.

LANA, G. R. Q.; ROSTAGNO, H. S.; DONZETE, J. L.; LANA, A. M. Q. Efeito de programas de restrição alimentar sobre o desempenho produtivo e econômico e a deposição de gordura na carcaça de frango de corte. Revista Brasileira de Zootecnia, Viçosa, v. 28, n. 6, p. 1302-1309, 1999.

NERES, M. A.; MONTEIRO, A. L. G.; GARCIA, C. A.; COSTA, C.; ARRIGONI, M. B.; ROSA, G. J. M. Forma física da ração e pesos de abate nas características de carcaça de cordeiros em creep feeding. Revista Brasileira de Zootecnia, Viçosa, v. 30, n. 3, p. 948-954, 2001.
ORTIZ, J. S.; COSTA, C.; GARCIA, C. A.; SILVEIRA, L. V. A. Medidas objetivas das carcaças e composição química do lombo de cordeiros alimentados e terminados com três níveis de proteína bruta em creep feeding. Revista Brasileira de Zootecnia, Viçosa, v. 34, n. 6, p. 2382-2389, 2005.

ROSA, G. T.; PIRES, C. P.; SILVA, J. H. S.; MULLER, L. Crescimento de osso músculos e gordura dos cortes da carcaça de cordeiros e cordeiras em diferentes métodos de alimentação. Revista Brasileira de Zootecnia, Viçosa, v. 31, n. 6, p. 2283-2289, 2002.

RUFINO, S. R. M. Desempenho de cordeiros confinados e em pastejo submetidos a diferentes tipos de suplementação. 2005. 42 f. Dissertação (Mestrado em Zootecnia) - Universidade Federal de Campina Grande, Patos, 2005.

SANIZ, R. D. Qualidade das carcaças e da carne ovina e caprina. In: SIMPÓSIO INTERNACIONAL SOBRE TÓPICOS ESPECIAIS EM ZOOTECNIA, 1., 1996, Fortaleza. Anais... Fortaleza: SBZ, 1996. p. 3-14.

SANTOS, E. M. Exigências nutricionais de energia e proteína e estimativa de consumo de ovinos em pastejo no semi-árido. 2006. 50 f. Dissertação (Mestrado em Zootecnia) - Universidade Federal de Campina Grande, Patos, 2006.

SAS INSTITUTE. Statistics Analysis Systems: user's guide. Washington, DC, 1999. $842 \mathrm{p}$.

SILVA SOBRINHO, A. G. Body composition and característics of carcass from lambs of different genotypes and ages at slaughter. Palmerston North: Massey University, 1999. 54 p. (Post. Doctorate in Sheep Meat Production).

SIQUEIRA, E. R. Produção de carne de cordeiros. In: ENCONTRO MINEIRO DE OVINOCULTURA, 1., 2000, Lavras. Anais... Lavras: UFLA, 2000. p. 129-149.

SIQUEIRA, E. R.; SIMÕES, C. D.; FERNANDES, S. Efeito do sexo e do peso ao abate sobre a produção de carne de cordeiros: morfometria da carcaça, peso dos cortes, composição tecidual e componentes não constituintes da carcaça. Revista Brasileira de Zootecnia, Viçosa, v. 30, n. 4, p. 1299-1307, 2001 